\section{The psychological effects of providing personal care to a partner: a multidimensional perspective}

\author{
Thomas Hansen, Britt Slagsvold \\ NOVA - Norwegian Social Research, \\ Oslo, Norway
}

\section{Abstract}

The expected increasing demand for informal care in aging societies underscores the importance of understanding the psychological implications of caregiving. This study explores the effect of providing regular help with personal care to a partner on different aspects of psychological well-being. We use cross-sectional data from the Norwegian Life Course, Ageing and Generation study (n. 15,000; age 40-84) and two-wave panel data from the Norwegian study on Life Course, Ageing and Generation (n. 3000; age 40-84). To separate the effects of providing care from those of the partner's disability, caregivers are contrasted with non-caregivers with both disabled and nondisabled partners. We separate outcomes into cognitive well-being (life satisfaction), psychological functioning (self-esteem, mastery), and affective well-being (happiness, depression, loneliness). Findings show that caregiving has important cross-sectional and longitudinal detrimental psychological effects. These effects are fairly consistent across all aspects of well-being, demonstrating that caregiving has a broad-based negative impact. Among women, however, these effects are similar to if not weaker than the effects of a partner's disability. Caregiving effects are constant by age, education, and employment status, but stronger among caregivers with health problems. Providing personal care to a partner is associated with marked adverse psychological effects for men and women irrespective of age and socio-economic status. Hence, no sociodemographic group is immune from caregiving stress, so programs should be targeted generally. The results also suggest that the health needs of caregivers demand more attention.

\section{Introduction}

The majority of older couples eventually experience one partner becoming ill or disabled and the other partner assuming the role of caregiver. The transition entails profound changes in the relationship and many carers experience a sense of loss, social isolation, limitations in their time use, financial concerns, and physical and psychological care strains. ${ }^{1}$ To care for an ailing partner can thus be a great burden and it is usually portrayed as such in public and private discourse. On the other hand, caregiving may also have positive aspects, such as increased closeness to the care recipient, social recognition, and satisfaction from doing one's duty or being there for the partner. Partner caregiving may thus have different effects-both positive and negative-on different aspects of psychological well-being. Effects may also vary by personal and situational factors.

Understanding when and how partner caregiving affects psychological well-being is important to identify and support caregivers who feel alone or overwhelmed. The expected increasing demand for informal care in aging societies further underscores this importance. Expenditure on long-term care (as a percentage of GDP) in most OECD countries is expected to a least double between 2010 and 2050.2,3 Western governments are thus trying to facilitate informal care provided by children and partners. ${ }^{4}$ Policymakers must however, weigh the intended benefits of informal care (reduced public costs and ensured eldercare) against the possible psychological costs of providing care. The strains of caregiving may be particularly pronounced for spousal caregiving, which, compared with parental caregiving, generally involves more hours of direct care and more responsibility for ensuring care is provided, and may have more impact on aspects of well-being such as social life and sleep. Social and psychological costs are likely to be particularly significant for those who provide personal care (e.g., help with dressing, bathing, eating). In the Nordic countries, family care usually consists of instrumental support, whereas long-term personal care is usually provided by the formal services. 5 Increasing longevity and aging of the population may, however, translate into greater need for informal help with personal care as well.

Despite a large literature on the psychological effects of informal caregiving, there are a number of gaps that prevent a nuanced understanding of the psychological implications of providing personal care to partner. First, studies typically fail to discriminate between different kinds of caregiving; different care chores (practical versus personal); different care recipients (e.g., a spouse versus a parent); and different care intensities (regular/frequent versus irregular/infrequent). As a result, empirical findings are ambiguous because they lump together caregivers who may be quite dissimilar.

Second, previous studies have not tried to disentangle the psychological effect of providing care from that of having a disabled family member. It is thus unclear whether it is care-
Correspondence: Thoms Hansen,

NOVA - Norwegian Social Research, 3223 Elisenberg, 0208 0slo, Norway.

Tel. +47.225.41200 - Fax: +47.225.41201

E-mail: han@nova.no

Key words: psychological well-being, caregiving, personal care, partner, Norway.

Contributions: TH, conception and design, analysis and interpretation of data, writing of the drafts and final version of the article; BS, conception and design, acquisition and interpretation of data, critical revisions to drafts and the final version of the article.

Conflict of interest: the authors declare no potential conflict of interests.

Funding: this research is supported by grants from the Norwegian Research Council (project EqualCare 196425/N50 and NorPAN 187783).

Received for publication: 2 January 2013. Revision received: 7 February 2013.

Accepted for publication: 7 February 2013.

This work is licensed under a Creative Commons Attribution NonCommercial 3.0 License (CC BYNC 3.0).

CC Copyright T. Hansen and B. Slagsvold., 2013

Licensee PAGEPress, Italy

Health Psychology Research 2013; 1:e25

doi:10.4082/hpr.2013.e25

giving in itself that affects well-being. In-depth interviews with spousal caregivers show that worry about the illness and its impact on the care recipient is experienced as more challenging than the care tasks. ${ }^{6,7}$

Third, the existing literature is largely American, with limited European and Nordic evidence. Because the impact of caregiving on well-being may vary according to institutional and cultural context, more research from nonUS settings is necessary. The Nordic countries are characterized by a comprehensive public sector and a strong preference for formal care. ${ }^{8,9}$ Thus, in these countries, because most individuals with extensive care needs receive public home care or reside in care institutions, the family rarely cares for elderly members in need of high levels of care.

Fourth, previous work has generally not examined moderating influences at the individual level. Caregivers are not a homogenous group and the consequences of providing care may vary according to individual and situational factors. For example, as will be elaborated below, the psychological effects of caregiving may vary by the caregiver's gender, age, educational level, and health status.

Fifth, there is a lack of longitudinal evidence. Cross-sectional analyses are unable to separate the effect of caregiving on well-being 
from that of the selection of mentally healthy persons into the caregiving role.

Finally, most studies have been limited by their scope of dependent variables, thus missing the complexity of the psychological effects of caregiving. Studies characteristically focus on only one or two aspects of psychological well-being, typically measures of psychological distress. Much less is known about the potential consequences of caregiving on variables such as happiness and loneliness. Little is also known about the possible gratifying or rewarding aspects of caregiving. Qualitative interviews show that informal carers may also experience feelings of appreciation, increased affinity with the care recipient, growth, and satisfaction in their role as caregiver, and that these rewards can co-exist with high levels of stress. ${ }^{10-12}$ More quantitative research is thus needed on variables such as self-esteem, mastery, and life satisfaction, which may be posited as enhanced by the experience and even the challenges of caregiving. 13

Psychological, or subjective, well-being can be conceptualized as comprising both a cognitive component, that is, cognitive well-being (satisfaction with life), and an affective component, that is, affective well-being. The latter is usually further subdivided into positive or pleasant affect (e.g., joy, pride, happiness) and negative or unpleasant affect (e.g., sadness, depression, loneliness). ${ }^{14} \mathrm{~A}$ third dimension can be added that transcends hedonic experiences and emphasizes positive psychological functioning (e.g., sense of control, selfesteem). ${ }^{15}$ Conceptually and empirically, these components are related yet distinct aspects of well-being. ${ }^{16}$ Because caregiving has a multifaceted impact (structural, social, financial, and existential) on people's lives and because the influence can be both positive and negative, the effects of caregiving on psychological well-being could vary substantially depending on the well-being aspect under scrutiny and the individual's other life circumstances. Caregivers may for example experience emotional distress but nevertheless believe that their lives are meaningful and rewarding. Therefore, studies should include measures that capture both the positive and negative components of psychological well-being and that are sensitive both to the day-to-day costs and the possible long-term or existential rewards of caregiving.

This paper explores the effect of providing regular personal care to a partner on life satisfaction, self-esteem, sense of control, happiness, depression, and loneliness. Although previous studies have examined some of these relationships, this is the first study to examine these relationships within a single study. We also investigate some potentially relevant moderators of these relationships, namely, the caregiver's age, educational level, employment status, and physical health. All analyses are done separately for men and women. To explore whether it is the caregiving or the partner's illness that affect well-being, we contrast caregivers with two groups of partnered non-caregivers: one group whose partners have a disability and another whose partners have no disability. We use both cross-sectional and panel data. The panel analysis examines whether caregiving predicts a change in wellbeing over the previous five years. Thus, the main contributions of this paper are that it uses a large, representative sample; goes into detail on the aspects of caregiving and wellbeing under scrutiny; aims to separate the effects of caregiving from those of a partner's disability; and uses both cross-sectional and panel data.

\section{Relationships between caregiving and different aspects of psycholog- ical well-being}

\section{Cognitive well-being}

Life satisfaction is an overall cognitive assessment of one's quality of life. 17 This evaluation is believed to result from people evaluating their lives according to various standards, such as their earlier lives, personal goals and expectations, and the expectations of significant others. ${ }^{18}$ Caregiving may thus depress positive self-evaluations because it usually represents a disruption of the expected and desired life course. Caregiving usually also requires a significant commitment of time and energy and entails major changes to roles and the relationship, which in turn may lower life satisfaction. On the other hand, caregiving entails opportunities for belonging, making a contribution and helping others, and receiving favorable feedback, which may promote wellbeing and positive self-evaluations.

\section{Psychological functioning}

With psychological functioning we here refer to internal psychological resources such as self-esteem and sense of mastery. Selfesteem is a global evaluation of self-worth, selfacceptance, and self-respect. ${ }^{19}$ Although stigmatization and feelings of inadequacy in the caregiver role may undermine self-esteem, the altruistic aspects of providing care may augment self-esteem and make caregivers feel like better people.

Mastery (or sense of control) refers to the extent to which individuals view themselves as personally powerful or influential in affecting important outcomes in their lives. ${ }^{20}$ On the one hand, successfully exerting control as a caregiver may promote a sense of mastery. On the other hand, the stressful and often uncontrollable aspects of caregiving may suppress the caregiver's perceived coping capacities.

\section{Affective well-being}

We consider three aspects of affective wellbeing: happiness, depression, and loneliness.

Happiness can be conceptualized as a global measure of positive affect. ${ }^{21}$ Depression is a mental health construct that refers to lowered mood, loss of interest, self-deprecation, and hopelessness. ${ }^{19}$ Depression can be conceived as a general measure of psychological distress or negative affect. ${ }^{22}$ Caregiving may increase psychological distress because it generates more daily problems, stress, and worries (about the care recipient, their own ability to meet future care needs, and prospects of receiving public support). The effect of caregiving on positive affect (happiness) is less clear. Caregiving may deplete energy and vitality; yet many caregivers report that caregiving promotes feelings of fulfillment and pride. ${ }^{12}$

Loneliness is defined as an unwelcome feeling of lack or loss of companionship, support, and intimacy. ${ }^{19}$ Caregivers may be susceptible to loneliness because they are restricted from pursuing social activities, or because they actively withdraw from social contact in response to the care recipient's situation. ${ }^{12}$

\section{Literature review}

Two meta-studies based on 228 (mostly US) papers examine relationships between caregiving and well-being. ${ }^{23,24}$ The studies show, first, that researchers typically adopt a broad definition and measurement of caregiving, encompassing all forms of assistance to persons in need of help because of poor health. Further, the studies show that a large literature relates caregiving to depression and psychological distress (caregiver burden), with a few papers linking caregiving to reduced subjective well-being. There is marked betweenstudy variability in these effects, which the authors explain by the fact that most studies are based on limited, non-representative convenience samples.

The meta-studies show that caregiving typically has more adverse emotional impacts on women and the elderly (ibid.). The authors propose that women are more affected by caregiving than men because women provide more care in general and more personal care especially, and because they more often experience social pressure to provide care. The authors relate more detrimental effects of caregiving in older age to fewer psychological, physical, and financial resources, and fewer stress-protective roles and activities.

The notion that caregiving has positive aspects is supported by a few studies. These show that, although caregiving relates to emotional distress, it may at the same time be associated with increasing self-esteem, mean- 
ing, engagement, and pride.1,25,26 These studies define care either as personal care or both practical and personal care to older persons.

Only a few studies have examined the psychological effects of caregiving using representative Nordic samples. One cross-sectional study examines the effect of providing practical help or personal care in a representative sample of Swedes aged 50-89 ( $\mathrm{n}=543$ caregivers), without distinguishing between different care recipients. ${ }^{27}$ It shows that intensive caregivers (those who provide help at least four times per week, 53 percent of whom provide personal care) report lower life satisfaction than other caregivers and non-caregivers. This study finds no effect of caregiving on loneliness, irrespective of care frequency.

We have in previous cross-sectional and longitudinal analyses of the same dataset as used here examined the emotional and psychological effects of providing regular personal care to a parent. ${ }^{28}$ Results show that providing such care is largely unrelated to psychological wellbeing, except among women who provide care in their own home; resident, but not non-resident, female caregivers report lower life satisfaction and higher psychological distress and depression than other women. The results indicate that it may be difficult to maintain well-being when the care becomes more extensive and when the relationship to the dependent is more proximate or intimate. Based on these findings, we expect that caring for a partner with needs connected to activities of daily living (ADLs) may undermine psychological well-being, and more so for women than men.

\section{Research questions}

We investigate two main research questions. We first ask whether i) having a disabled partner and ii) providing regular help to a partner with personal care are related to different aspects of psychological well-being. We have argued that while caregiving may cause psychological distress, it may promote meaning, a sense of mastery, and positive self-evaluation. The second question aims to identify subgroups of carers at risk of emotional distress. We ask whether the effects of caregiving on psychological well-being aspects are contingent upon (combinations of) the caregiver's gender, age, educational level, and employment and health status. We were unable to explore the moderating role of receipt of public care services, due to low response rates on questions about public care.

\section{Gender}

The literature has paid relatively little attention to how caregiving affects men. ${ }^{24,29}$ It is both timely and relevant to pay more attention to the experiences of male caregivers, as men have become gradually more involved in caregiving over the last decades. ${ }^{30}$ In a Norwegian study of people aged $80+$ with care needs, 25 percent report their principal caregiver to be a man. ${ }^{31}$ In addition, men may become even more involved in the future because of a greater need for informal care and greater gender equality in work and domestic roles, a development that is perhaps nowhere more evident than in the Nordic countries. ${ }^{32}$ Men's contribution may also increase because life expectancy is anticipated to increase more for men than for women. ${ }^{33}$ On the one hand, one might expect more detrimental psychological effects of caregiving for women, who generally carry a larger caregiving load and, more often than men, provide help without assistance or support from the public services or others. ${ }^{3}$ On the other hand, caregiving may represent specific challenges for men, insofar as men have less general care competency and caregiving represents a contrast to traditional and stereotypical constructions of masculinity.

\section{Age}

On the one hand, caregiving may be less demanding in older age, because of fewer responsibilities and role conflicts (e.g., between work and family). Also, in older age, caregiving may be expected. On the other hand, caregiving in older age may be more physically challenging, and more stressful because of fewer potentially stress-buffering roles and activities. Understanding such age variations may be of particular interest since greater longevity and possible compression of morbidity indicates that partner care in the future will be more often provided by individuals who are themselves old.

\section{Education}

More educated caregivers may have better coping skills, partly by being more adept at accessing services and using financial and social resources to alleviate the caregiver burden. However, more educated caregivers may be more vulnerable to role strain and have more difficulty accepting or handling the demands of caregiving. Increasing education in the population, especially among women, implies a higher educational level in future cohorts of caregivers.

\section{Employment}

It is open to question whether being in paid labor represents a source of (additional) stress or a source of diversion and respite for caregivers. In the future, because of growing female employment, increasing reliance on informal care, and raised retirement age, more people may be confronted with the double burden of work and caregiving duties.

\section{Health}

Caregivers with poor health may be particularly vulnerable to caregiver stress because of greater difficulties with practical demands, fatigue, pain, sleep problems, and lower family and professional support.

\section{Materials and Methods}

\section{Data}

This paper is based upon data from two overlapping datasets: cross-sectional data from the Life-Course, Generations and Gender (LOGG) study and two waves of data from the Norwegian Life Course, Ageing, and Generations (NorLAG) panel study.

LOGG comprises a nationally representative sample aged 18-84 $(n=15,109)$. Data was collected in 2007/2008, through (computer-assisted) telephone interviews and postal questionnaires (combined response rate 43.2 percent). Data from public registries were added with the respondents' informed consent. LOGG is part of the international Generations and Gender Study (GGS). ${ }^{34}$ We use the subsample of cohabiting or married individuals aged 40$84(\mathrm{n}=6734)$.

NorLAG comprises representative randomly stratified (by age and sex) samples of adults aged 40-79 (in wave 1) from 30 Norwegian municipalities representing different geographic regions. The first wave of data was collected in 2002/2003. The second wave was carried out as part of LOGG, in 2007/2008. Data was collected via telephone interviews, postal questionnaires, and registers. In all, 3792 respondents (response rate 45.5 percent) completed the telephone interview and postal questionnaire in both waves. We use the subsample of individuals who were cohabiting or married at $\mathrm{t} 1$ and $\mathrm{t} 2(\mathrm{n}=2553)$.

\section{Dependent variables}

This study uses six well-established measures of psychological well-being. Life satisfaction is measured by the Satisfaction With Life Scale (SWLS). 35 The scale comprises five items (e.g., I am satisfied with my life) measured on a 5 -point scale ( 1 = strongly disagree, $5=$ strongly agree). The composite index $(\alpha=0.76)$ ranges from 1 to 5 (high life satisfaction). Self-esteem is measured with Rosenberg's ${ }^{36}$ 10-item Self-Esteem Scale (RSES; e.g., I feel that I have a number of good qualities), with responses ranging from 1 (strongly disagree) to 5 (strongly agree). The composite index $(\alpha=0.80)$ ranges from 1 to 5 (high self-esteem). Mastery is measured by Pearlin and Schooler's ${ }^{37}$ 7-item Mastery Scale (PMS; e.g., I have little control over the things that happen to me, $\alpha=0.79$ ), with responses 
ranging from 1 (strongly agree) to 5 (strongly disagree). Happiness is measured with one item from the depression scale (I felt happy). Depression is measured with the 20-item Center for Epidemiologic Studies Depression (CES-D) scale. ${ }^{38}$ Respondents were asked to indicate on a 4-point scale ( 1 = rarely or none of the time, 4 = all of the time) how often they felt sad, depressed, that my sleep was restless, that my life has been a failure, etc., during the previous week. The index ranges from 1 to 4 (high depressive symptoms) $(\alpha=0.86)$. Loneliness is measured by eight items from the Loneliness Scale, ${ }^{39}$ measured on a scale from 1 to 5 (high loneliness) $(\alpha=0.81)$. Because NorLAG1 only includes three of these items (I miss having a really close friend; I find my circle of friends and acquaintances too limited; There are many people I can trust completely), only these three items are used in the panel analysis (the 3 -item index score is correlated 0.91 with the full scale). We have tested for high inter-correlations between dependent variables, but no variables correlate over 0.60 .

All the above outcome measures are widely used and show good psychometric properties, including validity, internal consistency, and test-retest reliability. 40 There are, however, other important issues to be addressed. One issue concerns the dimensionality of the scales. Many studies have supported a unidimensional model, documenting that a single latent factor accounts for a majority of the variance in item scores. The SWLS has since its inception been found to represent a single factor. ${ }^{41,42}$ The unidimensional structure also has been confirmed for the RSES, PMS, CES-D, and Loneliness scale. ${ }^{21}$ Another issue concerns the measurement invariance of the scales. As we find no obvious reason to expect differences by caregiver status in the manifestation of constructs, interpretation of items, or social desirability norms, we assume that the scales are relatively invariant across the comparison groups.

\section{Independent variables}

Caregiving (provision of personal care) is measured in LOGG by the question: Have you during the past year given regular help with personal care to someone? Help with, for example, eating, getting out of bed, dressing, or using the bathroom. We focus on those who have provided care to a spouse or cohabiting partner. We exclude $n=2$ individuals who provide personal care to a partner they do not live with.

Partner's disability (limiting longstanding illness). Individuals are classified as having a partner with a disability if stating that the partner has a longstanding illness, chronic health problem, functional disability, or mental problem and stating that the partner is limited in daily activities because of this health problem.

Information about gender, age, and educa- tion is gathered from public registers. Education ranges from primary (1) to college/university level (5). Employed individuals are those who report that they usually participate in paid work for 15 hours or more per week. The respondent's health is measured with the physical component of the 12-item Short Form Health Survey (SF-12, range 10.665.3). ${ }^{43}$

\section{Analytic strategy}

We use analysis of variance (ANOVA) and chi-square tests to analyze bivariate differences in means and proportions between groups according to caregiver status. All multivariate analyses use ordinary least squares (OLS) regressions. We use OLS regression for reasons of familiarity and ease of interpretation. Using OLS regression when the dependent variable is ordinal may be problematic as it violates the assumption of interval level data. We thus performed all the analyses using an ordinal-probit model (ancillary analyses), and the results were almost identical to those using OLS regression. It has been shown that the choice of methodology (OLS regression, ordinal-probit, or ordinal-logit techniques) in this context makes little difference to the empirical results. ${ }^{44}$ To determine whether the effect of caregiving status is modified by gender, age, education, or health, we estimated separate interaction models. We tested interaction effects by entering multiplicative terms involving one pair of predictors at a time, retaining main effects in the regression equations.

In the panel analyses, we examine effects of caregiving on well-being at time $2(\mathrm{t} 2)$, controlling for well-being at time 1 (t1). These effects can be interpreted as the effect of caregiving on change in well-being. ${ }^{45}$ Because caregiving was only measured at $\mathrm{t} 2$, we make the assumption that caregivers at $\mathrm{t} 2$ were not caregivers five years prior, at t1. Few elderly caregivers are likely to provide help with ADLs for such a long period in Norway. Older individuals with dependence in ADLs are likely, within a few years, to be either dead or - in the Norwegian welfare system - institutionalized or receiving extensive home care services. Romøren found, in a sample aged $80+$, that men and women on average live 3.2 and 1.8 years before death, respectively, with dependence in ADLs (which indicates need for personal care). 31

Analyses are run separately for men and women, and control for age, education, employment status, and health. Due to low statistical power in the panel analyses, a significance level of 0.10 is used ( 0.05 otherwise).

\section{Results}

\section{Cross-sectional analysis}

Table 1 shows the caregiver status among partnered individuals aged 40-84 in LOGG. As shown, 2.4 percent of men and 2.5 percent of women provide personal care, and 13.1 percent of men and 11.9 percent of women live with a disabled partner (but do not provide personal care). About 85 percent of men and women live with a nondisabled partner.

Table 1 also shows that caregivers are generally older than non-caregivers who have a disabled partner, who in turn are older than those with a nondisabled partner. These age differences mirror group differences in employment and health status, except that male caregivers report somewhat better health than male non-caregivers with a disabled partner. Caregivers tend to have more years of education than non-caregivers whose partners have a disability. This may suggest selection of people of higher socioeconomic status into the caregiver role. In ancillary analyses (not shown), female caregivers have significantly $(\mathrm{P}<0.05)$ higher mean and median income than women whose partner have a disability, whereas the opposite is true for men.

In Table 2 (men) and Table 3 (women), six aspects of well-being (life satisfaction, selfesteem, mastery, happiness, depression, and loneliness) are regressed on controls, caregiver status, and interactions between caregiver status and controls. Table 2 shows that, among men, there are no significant cross-sectional effects of having a disabled partner (compared with having a nondisabled partner), except a positive effect on loneliness. Providing personal care to a partner, however, has broad adverse effects on men's well-being (life satisfaction, self-esteem, mastery, happiness, and loneliness); yet caregiver status is unrelated to men's depressive symptoms (presented visually in Figure A and B in the Appendix).

The interaction analyses show that there are no significant $(\mathrm{P}<0.05)$ differences in the effects of caregiver status on men's well-being by age, education, and employment status. The respondents' physical health, however, moderates some of these relationships. The adverse effect of caregiving on men's life satisfaction, self-esteem, and mastery are stronger among men with poorer health.

Table 3 shows that, among women, providing personal care is associated with lower life satisfaction and mastery and more depressive symptoms and loneliness. These effects are also observed for women with a disabled partner. In addition, having a disabled partner is associated with lower self-esteem and happiness.

The interaction analyses show, among women, that age, education, and employment 
status do not moderate associations between caregiver status and well-being. Health, however, plays some role in these relationships. The adverse effects of caregiving and partner disability on life satisfaction, mastery, and loneliness are stronger among women with poorer health. In ancillary analyses, we tested gender differences in the effects of partner caregiving and a partner's disability (versus having a nondisabled partner). Having a disabled partner has stronger effects on women's than men's life satisfaction (coefficient $\alpha=-$ $0.12)$, mastery $(-0.10)$, happiness $(-0.13)$, and depression (0.06). Providing care has the largest effect on self-esteem (-0.08) and happiness $(-0.20)$ for men, and the largest impact on depression (0.10) for women (all $\mathrm{P}<0.05$ ).

Before moving on, it may be worth considering the practical significance of the results. Beyond statistical significance, how important are the effects of caregiving on psychological well-being? One way to elucidate effect size is to compare the magnitude of an effect with those of other known predictors. Health is known to be one of the most potent predictors of subjective well-being. Our measure of health has, after dividing it by 10 , a standard deviation of 1.0. In Tables 2-5, the effect (as measured by the unstandardized coefficient) of caregiving can be compared with that one standard deviation change in health. As shown, caregiving (versus having a healthy partner) consistently has larger impacts than a one standard deviation change in health. Some effects of caregiving (e.g., on happiness and loneliness among men, see Table 2) are comparable to those of more than two standard deviations change in health. This suggests that caregiving has substantive negative impacts on psychological well-being.

\section{Panel analysis}

As shown in Table 1, 3.1 percent of men and 2.6 percent of women aged $40+$ provide personal care to a partner in the NorLAG panel data, and 19.3 percent of men and 19.5 percent of women live with a disabled partner (but do not provide personal care). About 78 percent of men and women live with a nondisabled partner. Table 4 (men) and Table 5 (women) present the effects on well-being of caregiver status at 2 after controlling for (respective) indicator of well-being at $t 1$ (see also Figure $\mathrm{C}$ and $\mathrm{D}$ in the Appendix). Due to low statistical power in the panel analyses, a significance level of 0.10 is used. Generally, these longitudinal effects mirror the cross-sectional effects presented in Table 2 and Table 3.

Table 4 shows that, among men and consistent with the cross-sectional analyses (see Table 2), caregiving is associated with adverse five-year changes in all outcomes (life satisfaction, self-esteem, mastery, happiness, loneliness) except depression. Furthermore, these effects are significantly $(\mathrm{P}<0.10)$ or near-significantly $(\mathrm{P}<0.15$, not shown $)$ different from the effects of having a disabled partner.

Table 5 shows that, among women and consistent with the cross-sectional analyses (Table 3), caregiving is associated with declining well-being as measured by life satisfaction, mastery, and depression. Caregiving is unrelated to changes in self-esteem, happiness, and loneliness. Having a disabled partner is associated with broader negative changes in women's well-being than is providing care. Among women, partner disability is associated with declines in all well-being outcomes.

Tests of gender differences in the longitudinal effects of caregiving show that providing care has significantly $(\mathrm{P}<0.10)$ larger effects on happiness (0.43) and loneliness (0.33) among men, and a larger effect on depression (0.09) among women. We have also estimated the proportions of individuals who seem to show positive psychological effects related to caregiving. Table A in the Appendix show the percentages of individuals by caregiver status, net of controls, who report (change in) well-being one standard deviation above (life satisfaction, selfesteem, mastery, and happiness) or below (depression and loneliness) the mean level of (change in) well-being of the study sample. Measured this way, a substantial positive change in life satisfaction is only reported by 1 percent of male caregivers and 6 percent of female caregivers (versus 16 and 15 percent, respectively, among non-caregivers). Yet 13 percent of male caregivers and 10 percent of female caregivers (versus 13 and 16 percent among non-caregivers) report a positive change in self-esteem. In sum, although some people show positive psychological effects of caregiving, the mean effects are generally negative. The effects on well-being of caregiver status are quite consistent between the cross-sectional and longitudinal analyses but differ by gender and outcome variables. Men's well-being seems to be unaffected by the partner's disability, but negatively affected by providing care. Among men, adverse effects of caregiving are observed for all outcomes but depression. By contrast, women's well-being is more adversely associated with having a disabled partner than with providing personal care. Among women, partner disability is associated with detrimental crosssectional and longitudinal effects on all wellbeing outcomes. Providing personal care relates to lower life satisfaction, mastery, depression, and more loneliness, but is unrelated to women's self-esteem and happiness.

Table 1. Sociodemographic characteristics of the LOGG and NorLAG samples, by gender and caregiver status. Proportions (\%) or means (SD).

\begin{tabular}{|c|c|c|c|c|c|c|c|c|}
\hline & $\begin{array}{l}\text { Partner } \\
\text { caregiver }\end{array}$ & $\begin{array}{l}\text { Me } \\
\text { Non-caregiver, } \\
\text { disabled } \\
\text { partner }\end{array}$ & $\begin{array}{l}\text { Non-caregiver, } \\
\text { nondisabled } \\
\text { partner }\end{array}$ & Total & $\begin{array}{l}\text { Partner } \\
\text { caregiver }\end{array}$ & $\begin{array}{l}\text { Won } \\
\text { Non-caregiver, } \\
\text { disabled } \\
\text { partner }\end{array}$ & $\begin{array}{l}\text { Nen } \\
\text { Non-caregiver, } \\
\text { nondisabled } \\
\text { partner }\end{array}$ & Total \\
\hline \multicolumn{9}{|c|}{ LOGG } \\
\hline Age (40-84) & $63.16(11.33)$ & $59.59(11.02)$ & $56.49(10.79)$ & $57.06(10.92)$ & $60.91(11.59)$ & $57.96(10.19)$ & $54.27(10.10)$ & $54.87(10.27)$ \\
\hline Education (1-5) & $2.72(1.11)$ & $2.62(1.20)$ & $2.86(1.22)$ & $2.82(1.22)$ & $2.62(1.35)$ & $2.49(1.22)$ & $2.72(1.22)$ & $2.69(1.23)$ \\
\hline Employed (\%) & 31.9 & 45.2 & 69.0 & 56.4 & 30.2 & 43.8 & 67.3 & 53.7 \\
\hline Physical health & $47.31(9.27)$ & $46.61(11.12)$ & $50.27(8.67)$ & $49.72(9.13)$ & $44.83(12.80)$ & $45.21(12.05)$ & $48.42(10.33)$ & $47.95(10.67)$ \\
\hline $\mathrm{N}(\%)$ & $87(2.4)$ & $471(13.1)$ & $3037(84.5)$ & $3595(100)$ & $79(2.5)$ & $375(11.9)$ & $2685(85.5)$ & $3139(100)$ \\
\hline \multicolumn{9}{|c|}{ NorLAG panel (at t1) } \\
\hline Age (40-79) & $66.64(10.81)$ & $62.17(9.97)$ & $60.35(10.04)$ & $60.89(10.13)$ & $64.16(9.48)$ & $59.79(8.66)$ & $58.30(9.43)$ & $58.74(9.34)$ \\
\hline Education (1-5) & $2.79(1.24)$ & $2.59(1.22)$ & $2.88(1.23)$ & $2.82(1.24)$ & $2.81(1.45)$ & $2.54(1.19)$ & $2.70(1.23)$ & $2.67(1.23)$ \\
\hline Employed (\%) & 22.1 & 46.2 & 59.5 & 47.8 & 21.3 & 42.1 & 61.7 & 49.9 \\
\hline Health & $40.13(10.10)$ & $39.97(11.18)$ & $42.97(8.94)$ & $42.31(9.52)$ & 36.92 (13.94) & 38.23 (11.81) & 41.67 (10.32) & $40.88(10.83)$ \\
\hline $\mathrm{N}(\%)$ & $42(3.1)$ & $266(19.3)$ & $1069(77.6)$ & 1377 (100) & $31(2.6)$ & $229(19.5)$ & $916(77.9)$ & $1176(100)$ \\
\hline
\end{tabular}

All differences by caregiver status are statistically significant at $\mathrm{P}<0.05$. Caregiving is defined here as the provision of regular help with personal care. 


\section{Discussion}

As the aging population may translate into increased need for informal care, it is important to know when and how caregiving affects psychological well-being. Although many studies highlight the psychological effects of caregiving, they typically do not go into detail about the aspects about caregiving and well-being under scrutiny. In this paper we concentrate on personal care, because providing personal care is the most physically and emotionally challenging aspect of caregiving. We also concentrate on spousal caregiving, which is usually more extensive than parental caregiving. In contrast to previous work, we aim to distinguish the effects of providing care from those of a having a disabled partner. We examine cross-sectional and longitudinal effects of caregiving on altogether six aspects of wellbeing, as well as the moderating role of sociodemographic variables and health status. In a representative sample of Norwegians aged 40-84, less than 3 percent ( 6 percent in the ages 70-79) provide personal care to a partner.

Findings show that although some people show positive effects of providing care to a partner, it generally has deleterious effects on well-being. Caregiving is associated with marked reduction in cognitive well-being, psychological functioning, and affective wellbeing, with some differences by gender and outcome variables. More specifically, providing personal care to a partner, compared with having a nondisabled partner, has adverse cross- sectional and longitudinal relationships with life satisfaction, self-esteem (only among men), mastery, happiness (only among men), depressive symptoms (only among women), and loneliness (stronger effects among men). By contrast, we have previously found that providing regular personal care to a parent is largely unrelated to psychological well-being. ${ }^{28}$ This contrast suggests that different caregivers face different challenges and that interventions should pay special attention to providing support (e.g., respite) to spousal caregivers.

Caregiving effects on cognitive well-being likely indicate that caregiving represents an unwelcome and unexpected role - a disruption of the desired life course. Caregiving usually also requires significant commitment of time

Table 2. Regressing indicators of psychological well-being on caregiver status and interaction terms with controls for sociodemographic background variables and health. Unstandardized regression coefficients (men).

\begin{tabular}{|c|c|c|c|c|c|c|}
\hline & Life satisfaction & Self-esteem & Mastery & Happiness & Depression & Loneliness \\
\hline Age/100 & $0.45^{*}$ & $-0.28 *$ & $-0.92 *$ & $0.35^{* *}$ & -0.07 & $0.23^{* *}$ \\
\hline Education (1-5) & 0.01 & $0.05^{*}$ & $0.03^{*}$ & $-0.03 * *$ & $-0.01 * *$ & -0.00 \\
\hline Employed & 0.04 & $0.08 *$ & $0.14^{*}$ & 0.06 & $-0.06^{*}$ & $-0.08^{*}$ \\
\hline Health/10 & $0.14^{*}$ & $0.09 *$ & $0.17^{*}$ & $0.10^{*}$ & $-0.08^{*}$ & $-0.10^{*}$ \\
\hline $\begin{array}{l}\text { Caregiver status (CS) }^{\mathrm{a}} \\
\text { Nondisabled partner (1) } \\
\text { Disabled partner (2) } \\
\text { Caregiver (ref.) } \\
1 \text { versus } 2 \text { (sign.) }\end{array}$ & $\begin{array}{c}0.18^{*} \\
0.12^{* *} \\
-\end{array}$ & $\begin{array}{c}0.10^{* *} \\
0.03 \\
-\end{array}$ & $\begin{array}{l}0.21^{*} \\
0.16^{* *} \\
-\end{array}$ & $\begin{array}{l}0.25^{* *} \\
0.25^{* *} \\
-\end{array}$ & $\begin{array}{c}-0.04 \\
-0.03 \\
-\end{array}$ & $\begin{array}{c}-0.21 * \\
-0.09 \\
- \\
* *\end{array}$ \\
\hline $\begin{array}{l}\text { CS interactions } \\
\text { Health } \times \text { nondisabled partner } \\
\text { Health } \times \text { disabled partner } \\
\text { Health } \times \text { caregiver }(\text { ref.) }\end{array}$ & $\begin{array}{l}-0.10^{* *} \\
-0.06 \\
-\end{array}$ & $\begin{array}{c}-0.16^{* *} \\
-0.02 \\
-\end{array}$ & $\begin{array}{c}-0.18^{* *} \\
-0.06 \\
-\end{array}$ & $\begin{array}{c}-0.04 \\
-0.07 \\
-\end{array}$ & $\begin{array}{c}0.05 \\
0.01 \\
-\end{array}$ & $\begin{array}{c}0.02 \\
0.03 \\
-\end{array}$ \\
\hline Adj $R^{2}$ & 0.06 & 0.05 & 0.05 & 0.03 & 0.05 & 0.05 \\
\hline
\end{tabular}

Table 3. Regressing indicators of psychological well-being on caregiver status and interaction terms with controls for sociodemographic background variables and health. Unstandardized regression coefficients (women).

\begin{tabular}{|c|c|c|c|c|c|c|}
\hline & Life satisfaction & Self-esteem & Mastery & Happiness & Depression & Loneliness \\
\hline Age/100 & $0.35^{*}$ & $-0.33^{*}$ & $-0.90^{*}$ & -0.20 & 0.06 & 0.16 \\
\hline Education (1-5) & 0.00 & $0.05^{*}$ & 0.02 & 0.01 & $-0.02^{*}$ & $-0.04^{*}$ \\
\hline Employed & $0.09 * *$ & $0.11^{*}$ & $0.18^{*}$ & 0.08 & $-0.06^{*}$ & $-0.10^{*}$ \\
\hline Health/10 & $0.12^{*}$ & $0.08^{*}$ & $0.15^{*}$ & $0.05^{*}$ & $-0.06^{*}$ & $-0.06^{*}$ \\
\hline \multicolumn{7}{|l|}{ Caregiver status (CS) } \\
\hline Nondisabled partner (1) & $0.18^{*}$ & 0.03 & $0.16 * *$ & 0.05 & $-0.14 *$ & $-0.16^{*}$ \\
\hline Disabled partner (2) & 0.00 & -0.07 & 0.01 & -0.08 & -0.08 & -0.03 \\
\hline Caregiver (ref.) & - & - & - & - & - & - \\
\hline 1 vs. 2 (sign.) & ** & ** & $* *$ & ** & $* *$ & ** \\
\hline \multicolumn{7}{|l|}{ CS interactions ${ }^{\mathrm{a}}$} \\
\hline Health $\times$ nondisabled partner & $-0.06 * *$ & -0.04 & $-0.05^{* *}$ & -0.08 & 0.02 & $0.07 * *$ \\
\hline Health $\times$ disabled partner & $-0.08 * *$ & -0.05 & $-0.08 * *$ & -0.04 & 0.03 & $0.05^{* *}$ \\
\hline Health × caregiver (ref.) & - & - & - & - & - & - \\
\hline Adj $R^{2}$ & 0.06 & 0.05 & 0.05 & 0.03 & 0.05 & 0.05 \\
\hline
\end{tabular}

${ }^{*} \mathrm{P}<0.01 * * \mathrm{P}<0.05$. All dependent variables range from 1-5, except Happiness and Depression (1-4). Parameters not presented in the table (e.g., standardized coefficients, SE) are available upon request from the authors. LOGG data. alnteraction effects were tested entering one pair of predictors at a time in the regression equations. Interaction terms between caregiver status and age, education, and employment are not significant $(\mathrm{P}>0.05)$. 
and energy and entails major changes in the relationship, which in turn may lower life satisfaction. Caregiving may undermine psychological functioning (self-esteem and mastery) because of feelings of inadequacy in the caregiver role and because the stressful and often uncontrollable aspects of caregiving may suppress the caregiver's perceived coping capacities. Increasing loneliness may be a function of being prevented from pursuing social activities. ${ }^{12}$ As noted, caregiving seems to have more serious implications for men's than women's self-esteem, happiness, and loneliness. Explanations may be that men have less caregiving experience or that caregiving represents a contrast to the traditional male role. Also, more loneliness may reflect that men more than women identify their spouse as their best friend or only confidant. 46 Relationship changes caused by a partner's illness may thus be particularly consequential for his loneliness. Caregiving is unrelated to women's self-esteem and happiness. One interpretation is that the pro-social aspects of caregiving balance the demanding and dis- tressing aspects. Yet caregiving seems to evoke feelings of inadequacy and hopelessness (depressive symptoms) in women but not men. This contrast is consistent with research on the gendered causes of depression. A literature review shows that women are more likely than men to become depressed in the face of marital conflict and other interpersonal problems. ${ }^{47}$ Hence, disruption to conjugal roles (which may occur when a partner becomes sick or disabled) may elicit depressive reactions from women but not men. Among men, caregiving may produce some specific negative emotions (e.g., worries), but not depression, which is perhaps the most extreme form of negative affect.

Partner disability seems to be more consequential for women's than men's psychological well-being. Surprisingly, among women, the effects of partner disability are similar, if not stronger, than those of providing personal care to a partner. This finding is consistent with indepth interviews with spousal caregivers (mostly women) showing that the illness and worrying about the care recipient is experi- enced as more challenging than the care tasks. 6,7

The gendered partner disability effects are also consistent with previous research showing that the happiness and life satisfaction of women, but not of men, are reduced by their partners' disability. ${ }^{48,49}$ These declines in women's well-being are considerable, stable (not subject to adaptation), and not mediated by household income (ibid.). Similarly, a partner's health decline and onset of disability is found to decrease marital quality and increase divorce proneness more for wives than for husbands. 50 We can only speculate about possible answers to these pronounced gender differences. One speculation is that a partner's health problems interfere more strongly with women's than men's participation in personal and social activities. For example, men's illness has a larger impact on women's work engagements than vice versa. ${ }^{51}$

Other interpretations may draw on traditional gender roles and the assumption that, for older generations in particular, the man is supposed to be the strong one who takes care of

Table 4. Regressing indicators of well-being at time 2 on caregiving and interaction terms with controls for sociodemographic background variables, health, and time 1 well-being. Unstandardized regression coefficients (men).

\begin{tabular}{|c|c|c|c|c|c|c|}
\hline & Life satisfaction & Self-esteem & Mastery & Happiness & Depression & Loneliness \\
\hline Age/10 & -0.51 & -0.00 & $-0.01 * *$ & 0.06 & -0.02 & $0.04^{* *}$ \\
\hline Employed & -0.02 & 0.01 & 0.08 & 0.10 & -0.00 & 0.00 \\
\hline Education (1-5) & $-0.06^{* *}$ & -0.04 & $-0.06 * *$ & $-0.09^{* *}$ & -0.07 & -0.01 \\
\hline Health & $0.04^{* *}$ & 0.03 & $0.09 *$ & $0.05^{*}$ & $-0.05 *$ & $-0.10^{*}$ \\
\hline Well-being at tl & $0.39 *$ & $0.38 *$ & $0.25^{*}$ & $0.35^{*}$ & $0.31^{*}$ & $0.33^{*}$ \\
\hline $\begin{array}{l}\text { Caregiver status (CS) }^{\mathrm{a}} \\
\text { Nondisabled partner (1) } \\
\text { Disabled partner (2) } \\
\text { Caregiver (ref.) } \\
1 \text { vs. } 2 \text { (sign.) }\end{array}$ & $\begin{array}{c}0.18^{\circ} \\
0.16 \\
-\end{array}$ & $\begin{array}{c}0.12^{\circ} \\
0.11 \\
-\end{array}$ & $\begin{array}{c}0.14^{\circ} \\
0.11 \\
-\end{array}$ & $\begin{array}{c}0.37^{* *} \\
0.35^{* *} \\
-\end{array}$ & $\begin{array}{c}0.00 \\
-0.02 \\
-\end{array}$ & $\begin{array}{c}-0.33^{*} \\
-0.24^{*} \\
- \\
* *\end{array}$ \\
\hline $\operatorname{Adj} R^{2}$ & 0.42 & 0.52 & 0.33 & 0.14 & 0.34 & 0.28 \\
\hline
\end{tabular}

${ }^{*} \mathrm{P}<0.01,{ }^{*} \mathrm{P}<0.05{ }^{\circ} \mathrm{P}<0.10$. All dependent variables range from 1-5, except Happiness and Depression (1-4). Parameters not presented in the table (e.g., standardized coefficients, SE) are available upon request from the authors). alnteractions with age, education, employment status, and health are nonsignificant. NorLAG panel data.

Table 5. Regressing indicators of well-being at time 2 on caregiving and interaction terms with controls for sociodemographic background variables, health, and time 1 well-being. Unstandardized regression coefficients (women).

\begin{tabular}{|c|c|c|c|c|c|c|}
\hline & Life satisfaction & Self-esteem & Mastery & Happiness & Depression & Loneliness \\
\hline Age/10 & 0.01 & 0.00 & $-0.01 * *$ & -0.02 & -0.05 & $0.07 * *$ \\
\hline Employed & 0.00 & $0.09 * *$ & 0.10 & 0.03 & 0.02 & -0.01 \\
\hline Education (1-5) & -0.03 & -0.01 & $-0.11^{*}$ & -0.01 & $-0.12^{* *}$ & -0.01 \\
\hline Health & $0.08 *$ & $0.06^{*}$ & $0.10^{*}$ & $0.06^{*}$ & $-0.09 *$ & $-0.09 *$ \\
\hline Well-being at t1 & $0.41^{*}$ & $0.39 *$ & $0.23^{*}$ & $0.36^{*}$ & $0.32 *$ & $0.33^{*}$ \\
\hline $\begin{array}{l}\text { Caregiver status (CS) } \\
\text { Nondisabled partner (1) } \\
\text { Disabled partner (2) } \\
\text { Caregiver (ref.) } \\
1 \text { vs. } 2 \text { (sign.) }\end{array}$ & $\begin{array}{c}0.10^{\circ} \\
0.10 \\
- \\
*\end{array}$ & $\begin{array}{c}-0.10 \\
-0.03 \\
- \\
*\end{array}$ & $\begin{array}{c}0.14^{\circ} \\
-0.06 \\
- \\
\circ\end{array}$ & $\begin{array}{c}-0.06 \\
-0.26 \\
- \\
*\end{array}$ & $\begin{array}{c}-0.09^{\circ} \\
0.02 \\
- \\
* *\end{array}$ & $\begin{array}{c}-0.00 \\
-0.10 \\
- \\
* *\end{array}$ \\
\hline Adj R2 & 0.41 & 0.47 & 0.29 & 0.15 & 0.30 & 0.34 \\
\hline
\end{tabular}

${ }^{*} \mathrm{P}<0.01,{ }^{* *} \mathrm{P}<0.05,{ }^{\circ} \mathrm{P}<0.10$. All dependent variables range from 1-5, except Happiness and Depression (1-4). Parameters not presented in the table (e.g., standardized coefficients, SE) are available upon request from the authors). aInteractions with age, education, employment status, and health are nonsignificant. NorLAG panel data. 
the family. Accordingly, his health problems, because they threaten or interfere with traditional gender roles, may be more harmful to couples' well-being than her health problems (which may reinforce gender roles). We suggest two more specific pathways. First, to her, his disability may signal a loss of power and competence that affects her marital satisfaction and well-being directly. Second, his disability may also affect her well-being indirect$l y$. Research show that women's marital satisfaction and well-being are more strongly linked to their husbands' marital satisfaction and well-being than vice versa. ${ }^{4}$ Hence, when his health declines, his possible feelings of loss of masculinity and dissatisfaction may have spillover effects that reinforce her dissatisfaction with the confusion or reversal of gender roles. Other indirect evidence for the psychological impact of gender roles comes from longitudinal studies of unemployment, showing that (net of socio-economic factors) decreases in mental health and happiness are larger for both partners when the husband than when the wife enters unemployment. $49,52-54$

Caregiving has similar effects across sociodemographic strata. The robustness of caregiving effects by age, education, and employment status may reflect opposing mechanisms balancing each other out. For example, caregiving may be less psychologically demanding in older age because of fewer responsibilities and role conflicts (e.g., between work and family), yet also more demanding in older age because it is more physically challenging, and more stressful because of fewer potentially stress-buffering roles and activities. Furthermore, higher educated persons may be more vulnerable to role strain and have more difficulty accepting the demands of caregiving, yet cope better with the demands by being more adept at obtaining help from others and by relying on greater financial resources. Similarly, being in paid labor may represent both a source of (additional) stress and a source of diversion and respite for caregivers.

For caregiver support interventions, it is important to note that distress is exacerbated to caregivers who are themselves in poor health. This vulnerability may result from greater difficulties with practical demands, fatigue, pain, sleep problems, and lower family and professional support.

Before concluding, some limitations of this study should be noted. Interpretive caution is warranted because of the limited sample of carers. If the magnitude of a population effect is low to medium, then the effect may not be detectable in small samples due to large random sampling errors. ${ }^{55}$ Furthermore, because we lack information about caregiving at $\mathrm{t}$, we were unable to directly examine change in well-being in relation to change in caregiving status. There may be variation among caregivers' change in well-being depending on the length of caregiving. The more minor limitations are mentioned below.

\section{Conclusions}

We conclude by addressing implications for future research and social policy. We begin by highlighting three future research directions. First, this study underscores the multidimensionality of well-being and the need to consider and distinguish between different aspects of psychological well-being. A deep understanding is obscured if losing sight of the multidimensional implications of caregiving. The standard approach in the literature, which is to use only one outcome (typically a measure of psychological distress), not only misses the complexity of effects but also leads to an underestimation of the degree and breath of caregiver burden. Second, caregiving affects people differently. Non-significant or weak main and interaction effects may indicate a large amount of heterogeneity in the examined relationships. In other words, the pathways between caregiving and well-being may be complex, depending on combinations of a wide array of personal and situational factors. Third, findings suggest that future work should continue to attempt to separate caregiving and disability effects.

Furthermore, findings suggest at least four lessons for policymakers in aging societies. First, the challenges of assuming a caregiving role, although profound for both genders, may be more distressing for men than women. Becoming a caregiver is usually a gradual process linked with the partner's declining health. Among women, negative impacts seem to occur when the partner develops a health problem; among men when the partner develops needs in ADLs. The transition into a caregiver role may thus be more dramatic for men. Yet, on a positive note, these effects may attenuate in the future since men over the last decades have gained more nurturing and caregiving experience. ${ }^{30}$ Second, the current study and our previous work on parental caregiving show that there is no vulnerability associated with combining caregiving with paid labor - a combination that may become more common in the future. ${ }^{28}$ Some caution is warranted, however, as employment may have a stronger impact on caregiver distress at higher levels of working hours than we have examined (15 hours or more per week) or in countries with less flexible work arrangements than in Norway. Third, for social policy purposes it is also important to note that caregiver distress is more pronounced among caregivers who are themselves in poor health. Findings empha- size the need for support interventions to provide more comprehensive assistance to caregivers in poor health. Finally and most importantly, findings suggest that providing personal care to a partner has marked undesirable psychological implications for men and women from different sociodemographic strata. These implications are notably more pronounced than those of parental caregiving. What is more, a reduction in formal care and a stronger reliance on informal care may create even more caregiver distress. Policymakers should consider our findings and this concern when planning how to meet future needs for elder care services.

\section{References}

1. Marks NF, Lambert JD, Choi HJ. Transitions to caregiving, gender, and psychological well-being: A prospective US national study. J Marriage Fam 2002;64: 657-67.

2. Eurostat. Active ageing and solidarity between generations: a statistical portrait of the European Union 2012. Availablee from: http://epp.eurostat.ec. europa.eu/ cache/ITY_OFFPUB/KS-EP-11-001/EN/KSEP-11-001-EN.PDF.

3. OECD. Help wanted? Providing and paying for long-term care. Paris: OECD; 2011.

4. Huber M, Rodrigues R, Hoffman F, et al. Facts and figures on long-term care: Europe and North America. Vienna: European Centre for Social Welfare Policy and Research; 2009.

5. Daatland S0, Herlofson K, Lima I. Balancing generations: on the strength and character of family norms in the West and East of Europe. Ageing Soc 2011;31: 1159-79.

6. Gautun H, Werner A, Luras H. Care challenges for informal caregivers of chronically ill lung patients: results from a questionnaire survey. Scand J Public Health 2011;40:18-24.

7. Cheung J, Hocking P. Caring as worrying: the experience of spousal carers. J Adv Nurs 2004;47:475-82.

8. Rostgaard T, Szebehely M. Changing policies, changing patterns of care: Danish and Swedish home care at the crossroads. Eur J Ageing 2012;9:101-9.

9. Daatland S0, Lowenstein A. Intergenerational solidarity and the family-welfare balance. Eur J Ageing 2005;2: 174-82.

10. Ekwall AK, Hallberg IR. The association between caregiving satisfaction, difficulties and coping among older family caregivers. J Clin Nurs 2007;16:832-44. 
11. Grant G, Nolan M. Informal carers: sources and concomitants of satisfaction. Health Soc Care Comm 1993;1:147-59.

12. Toljamo M, Perala ML, Laukkala H. Impact of caregiving on Finnish family caregivers. Scand J Caring Sci 2012;26:211-18.

13. Marks NF, Bumpass L, Jun HJ. Family roles and well-being during the middle life course. In: Brim OG, Ryff CD, Kessler R, eds. How healthy are we? A national study of well-being at midlife. Chicago: University of Chicago Press; 2004. pp 514549.

14. Diener E, Suh EM, Lucas RE, Smith HL. Subjective well-being: three decades of progress. Psychol Bull 1999;125:276-302.

15. Ryff CD, Love GD, Urry $\mathrm{HL}$, et al. Psychological well-being and ill-being: do they have distinct or mirrored biological correlates? Psychother Psychosom 2006;75:85-95.

16. Lucas RE, Diener E, Suh E. Discriminant validity of well-being measures. J Pers Soc Psychol 1996;71:616-28.

17. Diener E. Subjective well-being. Psychol Bull 1984;95:542-75.

18. Michalos AC. Multiple discrepancies theory (MDT). Soc Ind Res 1985;16:347-413.

19. Bowling A. Measuring health: a review of quality of life measurement scales. 3rd ed. Maidenhead: Open University Press; 2005.

20. Pearlin L, Menaghan E, Lieberman M, Mullan J. The stress process. J Health Soc Behav 1981;22:337-56.

21. Hansen T. Subjective well-being in the second half of life: the influence of family and household resources. PhD dissertation. University of Oslo; 2010.

22. Mirowsky J, Ross CE. Social causes of psychological distress. 2nd ed. New York: Aldine de Gruyter; 2003.

23. Pinquart M, Sörensen S. Associations of stressors and uplifts of caregiving with caregiver burden and depressive mood: a meta-analysis. J Gerontol B Psychol Sci Soc Sci 2003;58:112-28.

24. Pinquart M, Sörensen S. Differences between caregivers and noncaregivers in psychological health and physical health: a meta-analysis. Psychol Aging 2003;18:25067.

25. Kramer BJ. Gain in the caregiving experience: Where are we? What next? Gerontologist 1997;37:218-32.

26. Marks NF. Does it hurt to care? Caregiving, work-family conflict, and midlife wellbeing. J Marriage Fam 1998;60:951-66.

27. Borg C, Hallberg IR. Life satisfaction among informal caregivers in comparison with non-caregivers. Scand J Caring Sci 2006;20:427-38.

28. Hansen T, Slagsvold B, Ingebretsen R. The strains and gains of caregiving: an examination of the effects of providing personal care to a parent on a range of psychological outcomes. Soc Ind Res 2012 [Epub ahead of print].

29. Winqvist M. Individualisering, utvärdering och utveckling av anhörigstöd. En kunnskapsoversikt. Kalmar: Nationellt kompetenscentrum Anhöriga; 2010.

30. Carmichael F, Charles S. The opportunity costs of informal care: does gender matter? J Health Econ 2003;22:781-803.

31. Romøren TI. Den fjerde alder. Funksjonstap, familieomsorg og tjenestebruk hos mennesker over 80 år. 0slo: Gyldendal; 2001.

32. Mencarini L, Sironi M. Happiness, housework and gender inequality in Europe. Eur Sociol Rev 2012;28:203-19.

33. Keilman N, Christiansen S. Norwegian elderly less likely to live alone in the future. Eur J Popul 2010;26:47-72.

34. Vikat A, Speder Z, Beets G, et al. Generations and Gender Survey (GGS): towards a better understanding of relationships and processes in the life course. Demogr Res 2007;17:389-439.

35. Pavot W, Diener E, Colvin CR, Sandvik E. Further validation of the satisfaction with life scale: evidence for the cross-method convergence of well-being. J Pers Ass 1991;57:149-61.

36. Rosenberg M. Society and the adolescent self-image. Princeton: University Press; 1965.

37. Pearlin L, Schooler C. The structure of coping. J Health Soc Behav 1978;19:2-21.

38. Radloff LS. The CES-D scale: a self-report depression scale for research in the general population. Appl Psychol Meas 1977;1:385-401.

39. de Jong-Gierveld J, van Tilburg T. Manual of the loneliness scale. Amsterdam: Vrije Universiteit; 1999.

40. Robinson JP, Shaver PR, Wrightsman LS. Measures of personality and social psychological attitudes. San Diego: Academic Press; 1991.

41. Tucker KL, Ozer DJ, Lyubomirsky S, Boehm JK. Testing for measurement invariance in the Satisfaction with Life Scale: a comparison of Russians and North Americans. Soc Ind Res 2006;78:341-60.

42. Diener E, Emmons RA, Larsen RJ, Griffin
S. The satisfaction with life scale. J Pers Ass 1985;49:71-5.

43. Ware JE, Kosinski M, Keller SD. A 12-item short-form health survey: construction of scales and preliminary tests of reliability and validity. Med Care 1996;34:220-33.

44. Ferrer-i-Carbonell A, Frijters P. How important is methodology for the estimates of the determinants of happiness? Econ J 2004;114:641-59.

45. Johnson D. Two-wave panel analysis: comparing statistical methods for studying the effects of transitions. J Marriage Fam 2005;67:1061-75.

46. Umberson D, Chen MCD, House JS, et al. The effect of social relationships on psychological well-being: are men and women really so different? Am Sociol Rev 1996;61:837-57.

47. Worell J. Encyclopedia of women and gender: sex similarities and differences and the impact of society on gender. San Diego: Academic Press; 2001.

48. Braakman N. The consequences of own and spousal disability on labor market outcomes and subjective well-being: evidence from Germany. Rev Econ Household [In press].

49. Winkelmann R, Winkelmann L. Happiness and unemployment: a panel data analysis for Germany. Konjunkturpolitik 1995;41: 293-307.

50. Yorgason JB, Booth A, Johnson D. Health, disability, and marital quality: is the association different for younger versus older cohorts? Res Aging 2008;30:623-48.

51. Lima JC, Allen SM, Goldscheider F, Intrator 0 . Spousal caregiving in late midlife versus older ages: implications of work and family obligations. J Gerontol B Psychol Sci Soc Sci 2008;63:229-38.

52. Marcus J. The effect of unemployment on the mental health of spouses: evidence from plant closures in Germany. Berlin: DIW; 2012.

53. Knabe A, Schöb R, Weimann J. Partnership, gender roles and the wellbeing cost of unemployment. Magdeburg: Magdeburg University; 2012.

54. McKee L, Bell C. His unemployment, her problem: the domestic and marital consequences of male unemployment. In: Allen S, Waton S, Purcell K, Wood S, eds. The experience of unemployment. Basingstoke: Macmillan; 1986.

55. Rosenthal R. Meta-analytic procedures for social research. Beverly Hills: Sage; 1991. 